\title{
Synthesis of new riboflavin modified ODNs: effect of riboflavin moiety on the G-quadruplex arrangement and stability
}

Valeria Romanucci ${ }^{*}{ }^{\dagger}$, Rosario Oliva ${ }^{a, b} \dot{\dagger}$, Luigi Petraccone ${ }^{a}$, Sandra Claes $^{c}$, Dominique Schols ${ }^{c}$, Armando Zarrelli ${ }^{a}$ and Giovanni Di Fabio ${ }^{* a}$

a. Department of Chemical Sciences, University of Napoli Federico II, Complesso di Monte Sant'Angelo, Via Cintia 4, I-80126 Napoli, Italy.

b. Physical Chemistry I - Biophysical Chemistry, TU Dortmund University, Otto-Hahn Strasse 4a, D-44227 Dortmund, Germany.

c. Department of Microbiology, Immunology and Transplantation, Rega Institute, KU Leuven, Herestraat 49, 3000 Leuven, Belgium.

$\dagger$ These authors contributed equally

*Corresponding authors:

Valeria Romanucci

e-mail address: valeria.romanucci@ unina.it

Giovanni Di Fabio

e-mail address: difabio@unina.it

Keywords: modified ODNs, G-quadruplex, riboflavin, chemical modification, DSC, CD. 


\begin{abstract}
In the panorama of modified G-quadruplexes (G4s) with interesting proprieties, here, it has been reported the synthesis of new modified d(TGGGAG) sequences forming G-quadruplexes, with the insertion of a riboflavin unit ( $\mathrm{Rf}$, vitamin $\left.\mathrm{B}_{2}\right)$. Exploiting the flavin similarity with the hydrogen bond pattern of guanine and aiming at mimic a typical nucleoside scaffold, the synthesis of the riboflavin building block 3 it has been efficiently carried out. The effect of insertion of riboflavin mimic nucleoside on the G-quadruplex properties has been here, for the first time investigated. A biophysical characterization of Rf-modified sequences (A-D) has been carried out by circular dichroism (CD), fluorescence spectroscopy, differential scanning calorimetry (DSC) and native gel electrophoresis. CD and electrophoresis data have suggested that Rf-modified sequences are able to form parallel tetramolecular G4 structures similar to that of the unmodified sequence. Analysis of the DSC thermograms has revealed that all modified G-quadruplexes have a higher thermal stability compared with the natural sequence, particularly the stabilisation is higher when the Rf residue is introduced at the 3'-end. Further, DSC analysis has revealed that the Rf residues introduced at the 3'-end are able to form additional stabilising interactions, energetically almost comparable to the enthalpic contribution of a Gtetrad. Fluorescence measurement are consistent with this result showing that the Rf residues introduced at 3'-end are able to form stacking interactions with the adjacent bases within the G-quadruplex structure. The whole of data suggested that the introduction of Rf unit can stabilize G-quadruplex structures and can be a promising candidate for future theranostic applications.
\end{abstract}




\section{Introduction}

G-quadruplexes (G4s) are non-canonical DNA structures which are formed and stabilized by stacked G-tetrads. Each G-tetrad contains four guanines associated through hydrogen bonding between Hoogsteen face (O6 and N7) in order to form a planar structure also called G-quartet stabilized by monovalent cations as $\mathrm{K}^{+}, \mathrm{Na}^{+}$and $\mathrm{NH}_{4}^{+}$which interact with the lone pairs on the $\mathrm{O} 6$ atoms surrounding the central core. Over the last years, G-rich oligonucleotides able to form G4, have attracted considerable interest in a large variety of fields including medicinal chemistry, supramolecular chemistry, and nanotechnology [1,2]. Several reports deserved particular attention to the elevated fascinating polymorphism of G-quadruplex structures that seems to be strongly implicated in their biological activity $[3,4]$. Moreover, the understanding of the marked polymorphism of nucleic acids is essential in the drug design and for the study of complex biological mechanisms [5]. Many reports in the last years have investigated how chemical modifications to the bases or the backbone of oligonucleotides forming Gquadruplexes effect the features of these higher-order structures [6-11]. G-quadruplexes have been recognized as a highly appealing DNA structures implicated in several diseases as cancer [12,13], neurodegeneration [14] and HIV infection [15-16]. In this regard, some G-quadruplex aptamers have been found to be active at different stages of HIV infection [17]. Among G4 discovered to be potent antiHIV aptamers, many reports described the activity of the Hotoda's sequence. This short d(TGGGAG) sequence forms a very stable parallel tetramolecular G4 and showed significant anti-HIV activity [18]. Taking advantage on our extensive knowledge about d(TGGGAG) sequence [19-21], we synthesized new modified d(TGGGAG) sequences with the insertion of a riboflavin moiety in different position of the sequence.

Riboflavin (Rf) is an essential water-soluble vitamin, precursor of flavin-based redox cofactors FMN and FAD. Rf presents interesting biological and physicochemical properties such as transporter specific cell internalization, implication in redox reactions and photosensitizer [22]. Rf and its derivatives FMN and FAD may serve as highly versatile building blocks for the construction of complex systems [23]. Over the years, many reports described the synthesis of a variety of Rf derivatives including polymers [24], proteins [25] and nucleic acids [26]. Regarding the latter case, the Rf ligand ability has been studied for the selective binding into DNA-duplex aptamers containing abasic site and also as DNA Gquadruplex ligand for biosensor applications [27]. In 1995, Riboflavin was also found to specifically bind RNA aptamer containing G-quartet structure [28]. Very recently, it has been shown that the Rf fluorescence is quenched when bound to G-quadruplex structure respect to single stranded form [29,27]. 
Further, several studies have shown the Rf ability to form non-covalent bonds such as p-p stacking [24], hydrogen [30], or electrostatic interactions [31].

In this work, we report the synthesis, biophysical and biological characterization of new Rf-modified sequences. The d(TGGGAG) sequence has been used as a model of parallel tetramolecular G4 structure. The insertion of riboflavin into lead sequence has been inspired by its similarity with the Hoogsteen hydrogen bond pattern of guanine combined with its excellent fluorescence properties that may be a useful tool for theranostic applications which involve the combination of therapy and diagnostic imaging into an unique system.

To explore how riboflavin unit affects the G quadruplex structure and if is able to additionally stabilize the G-quartet stacking, new Rf-modified sequences (A-D) have been investigated through different techniques in a combined approach (CD, DSC, native electrophoresis and fluorescence). Moreover, the anti-HIV activity of all sequences has been evaluated. 


\section{Results and Discussion}

\subsection{Synthesis of riboflavin-building blocks and insertion into the lead sequence}

The synthetic effort has been devoted for the synthesis of nucleoside-riboflavin building block $\mathbf{3}$, in particular aiming to make riboflavin moiety similar to a nucleoside unit, the ribityl chain has been rigidified with 2',4'-O-benzylidene protection. This synthetic procedure has been inspired by a previous study described by Schwogler et al. that reported the incorporation of $\mathrm{Rf}$ moiety into duplex DNA sequence by H-phosphonate chemistry.[32] Interestingly, even if we followed the same experimental conditions to obtain a selective benzylidene protection, we did not observe similar yield of the desired diastereoisomer 2 (22\% respect to $50 \%$ previously reported).

After benzylidene protection, the primary hydroxyl group of ribityl chain has been protected with DMT group, indeed the 3'-OH group has been functionalized with phosphoramidite (intermediate 4). [33] The

synthetic approach takes advantage from the different reactivity of primary and secondary hydroxyl groups following the classic nucleoside/tide chemistry. All intermediates were gained in very good yields (Scheme 1), only the intermediate 2 was obtained with a yield not greater than $22 \%$. An efficient postassembling conjugation to lead sequences provided to the Rf-modified sequences $\mathbf{A}$ and $\mathbf{B}$. Conversely, in order to synthesize the 3'-modified sequences $\mathbf{C}$ and $\mathbf{D}$, it has been again useful the key intermediate 3. The riboflavin functionalized support 6 has been obtained by succinylation of the free hydroxyl group (3'-OH) of intermediate $\mathbf{3}$ and subsequent solid phase reaction of $\mathbf{5}$ with a CPG support. New modified oligonucleotides (ODNs) were purified by RP-HPLC and finally analyzed by MALDI-TOF. The stability of benzylidene protection of the final Rf-modified ODNs was evaluated by HPLC analysis; the results confirmed its high stability, even during the acid treatment carried out in the ODN assembly. None cleavage it was observed. 

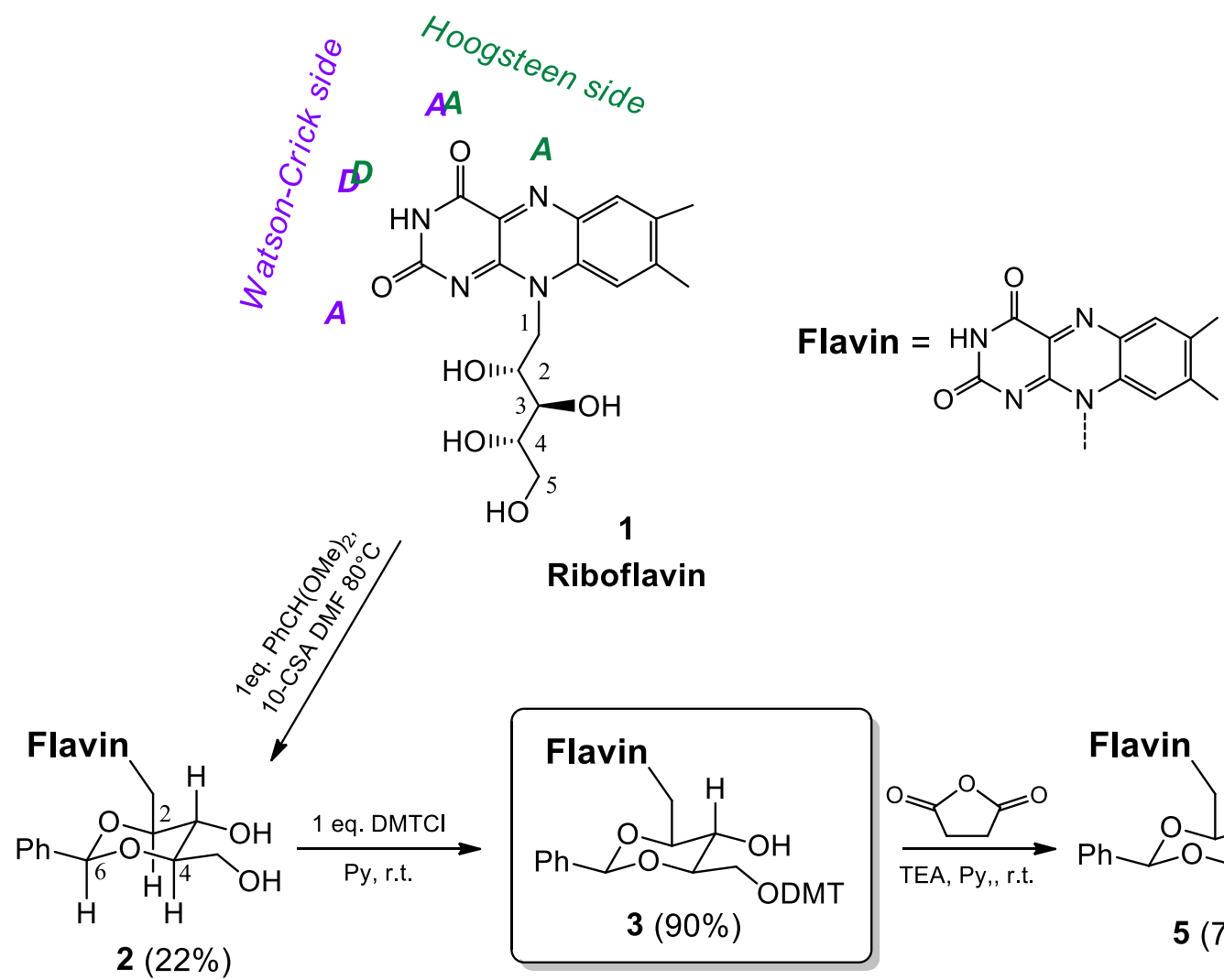

Riboflavin
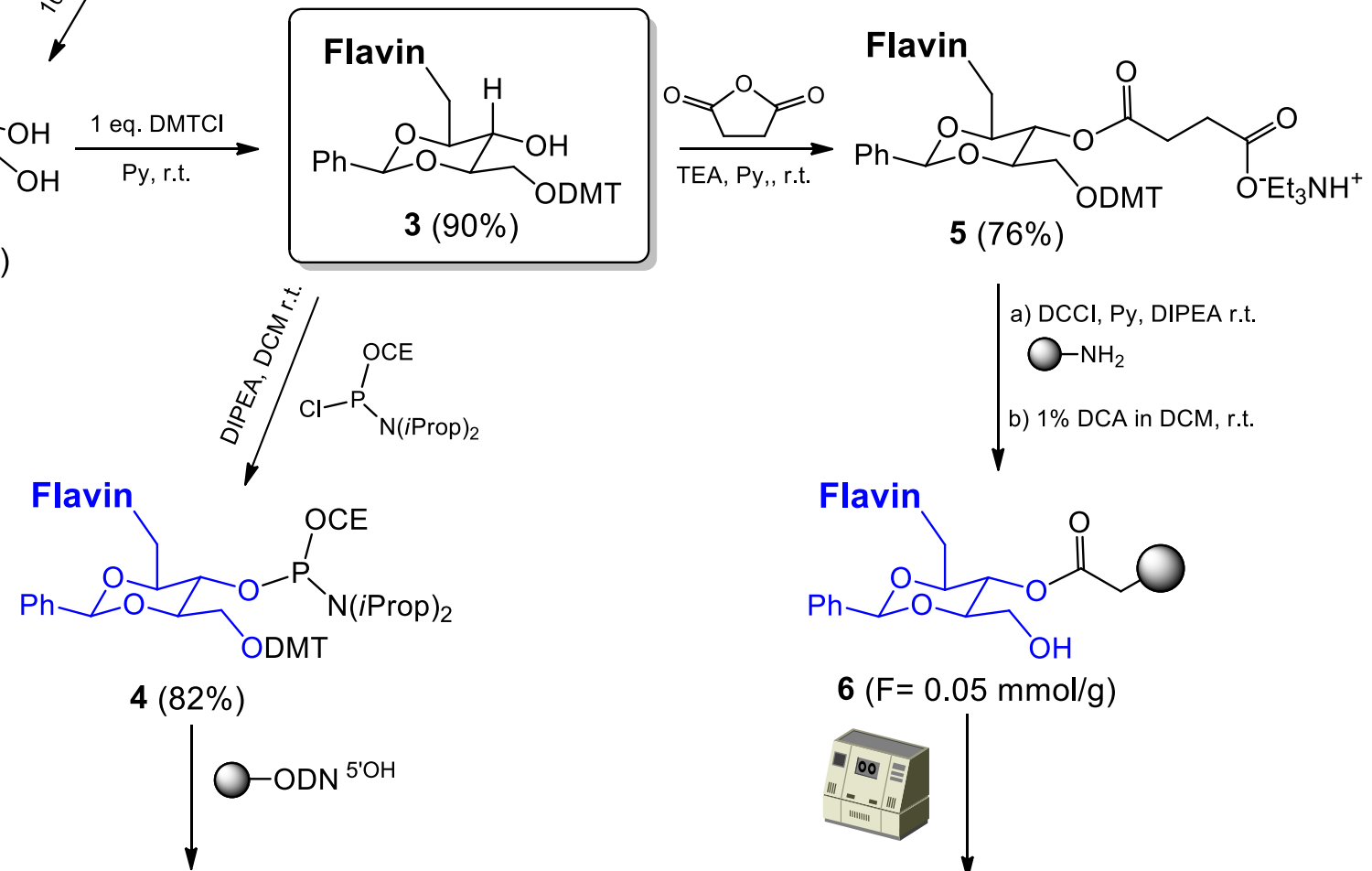

Rf-p-TGGGAG (A, 25\%)

Rf-p-GGGAG (B, 27\%)
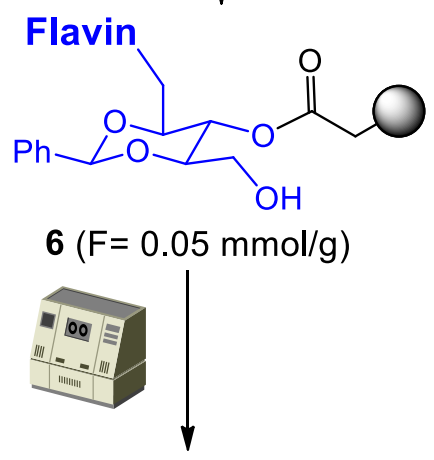

TGGGAG-p-Rf $(\mathbf{C}, 28 \%)$

TGGGA-p-Rf (D, 31\%)

Scheme 1. Synthetic scheme of riboflavin building blocks $\mathbf{3}$ and $\mathbf{5}$ and solid phase synthesis of Rfmodified A-D sequences. 


\subsection{Native gel electrophoresis of Rf-modified sequences defined the molecularity of complexes}

In order to determine the stoichiometry of resulting structures formed by Rf-modified ODNs, nondenaturing polyacrylamide gel electrophoresis (PAGE) experiment has been performed. Aiming at observing the mobility of all complexes, $\left[\mathrm{d}\left(\mathrm{TG}_{4} \mathrm{~T}\right)\right]_{4}$ and $\mathrm{d}\left(\mathrm{T}_{6}\right)$ were loaded as $\mathrm{G} 4$ and single stranded references, natural d(TGGGAG) and modified sequences (A-D) were loaded on the gel in single stranded (ss) conditions (no potassium added, indicated by "-") and G4 conditions (10 mM phosphate buffer + $100 \mathrm{mM} \mathrm{KCl}$, indicated by “"+”, see paragraph 4.5.1). In absence of potassium, as expected, all the sequences show a single well defined band corresponding to the single-stranded form (Fig. 1).

The addition of potassium is central to induce the G-quadruplex folding, in fact in presence of $\mathrm{K}^{+}$, this band disappears and a single band at lower mobility was observed for $\mathbf{A}, \mathbf{C}$ and $\mathbf{D}$. This behavior is similar to the one observed for the d(TGGGAG) and is consistent with the formation of G-quadruplex structures. The variation in the electrophoretic mobility of both ss and G4 forms of modified A-D sequences respect to the natural ones, is due to the contribute of Rf moiety and its interaction within the sequence depending on its position in it.[34,21] Only the sequence $\mathbf{B}$ presents a smearing retarded band (Fig. 1) suggesting the not complete formation of the tetramolecular complex and/or the formation of additional lower molecularity complexes.

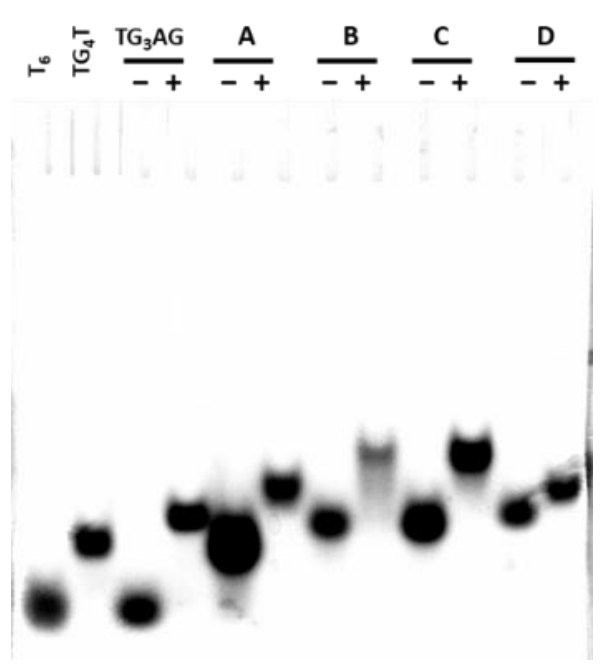

Fig. 1. Native gel electrophoresis of natural sequence d(TGGGAG) and Rf-modified sequences A-D sequences loaded at $50 \mu \mathrm{M}$ (ss concentration) in two conditions ("-", no potassium added; "“+" $100 \mathrm{mM}$ $\mathrm{KCl}$ ); $15 \%$ polyacrylamide gel supplemented with $10 \mathrm{mM} \mathrm{KCl}$. The gel was run at $26{ }^{\circ} \mathrm{C}$ at constant voltage $(90 \mathrm{~V})$ for $2.0 \mathrm{~h}$. 
2.3 CD profiles of Rf-modified sequences confirmed the formation of parallel $G$ quadruplex structures

The sequences $\mathbf{A}$ and $\mathbf{D}$ presented an additional Rf unit at 5'and 3'-end of d(TGGGAG) sequence, instead in $\mathbf{B}$ and $\mathbf{C}$ sequences, the 5'and 3' terminal bases were replaced with the $\mathrm{Rf}$ unit.

All secondary structures formed by Rf-modified sequences (A-D) have been characterized by CD in order to evaluate how the insertion of riboflavin moiety into d(TGGGAG) sequence influences its Gquadruplex arrangement. CD experiments have been performed in potassium buffer (10 mM $\mathrm{KH}_{2} \mathrm{PO}_{4} / \mathrm{K}_{2} \mathrm{HPO}_{4}+100 \mathrm{mM} \mathrm{KCl}$, see paragraph 4.5.1). As shown in the CD spectra reported in Fig. 2, the G4 arrangements of A-D sequences except $\mathbf{B}$, are similar to that adopted by natural d(TGGGAG) sequence with a typical profile of a parallel G4 structure characterized by a positive band at $263 \mathrm{~nm}$ and a negative band at $243 \mathrm{~nm}$.[35] On the other hand, the CD spectrum of $\mathbf{B}$ appears less intense compared to the other sequences. This behavior could be the result of a not complete G-quadruplex formation as already observed by gel electrophoresis. Small differences in the A-D CD profiles indicate slight structural or conformational variations in the modified G-quadruplexes due to not identical ODN sequences and also for the contribution of the riboflavin mimic nucleoside.[9]

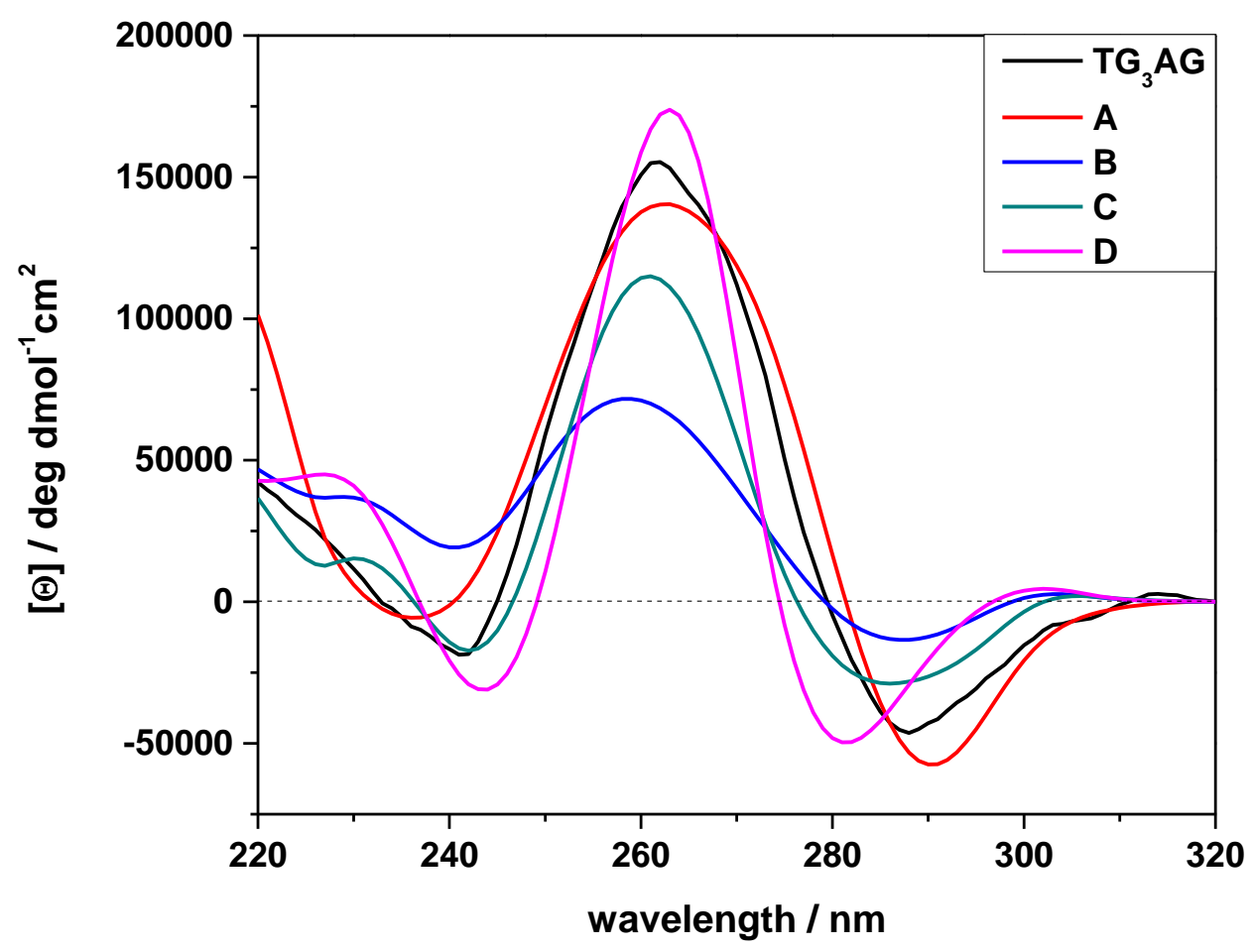

Fig. $2 \mathrm{CD}$ spectra of natural sequence d(TGGGAG) and Rf-modified A-D sequences (1x10-4 M ss concentration) registered in $10 \mathrm{mM}$ phosphate buffer $(\mathrm{pH}=7.0)$ containing $100 \mathrm{mM} \mathrm{KCl}$. 


\subsection{DSC characterization of modified G-quadruplexes unfolding}

The thermal unfolding of the studied complexes was followed by means of differential scanning calorimetry. In Fig. 3 the heating and cooling DSC profiles for the modified sequences are shown. For all samples the formation of the G-quadruplexes (an esothermic peak) was not observed in the cooling profiles, this indicates that the formation/dissociation of the complexes is not at thermodynamic equilibrium during the heating and cooling experiments.[36] This result, observed also for the natural sequence (Fig. S1), is in agreement with the well-known slow kinetics of tetramolecular G-quadruplexes folding.[36,37]

On the other hand, successive heating scans of the modified sequences were superimposable indicating that, at ODN concentrations of DSC experiments, few minutes at low temperature (before each temperature scan the sample was equilibrated at $5{ }^{\circ} \mathrm{C}$ for 15 minutes) were enough to allow the formation of these G-quadruplexes (Fig. S2). Interestingly, this result reveals that the introduction of the Rf residue increases the G4 formation kinetics in comparison with the unmodified sequence.
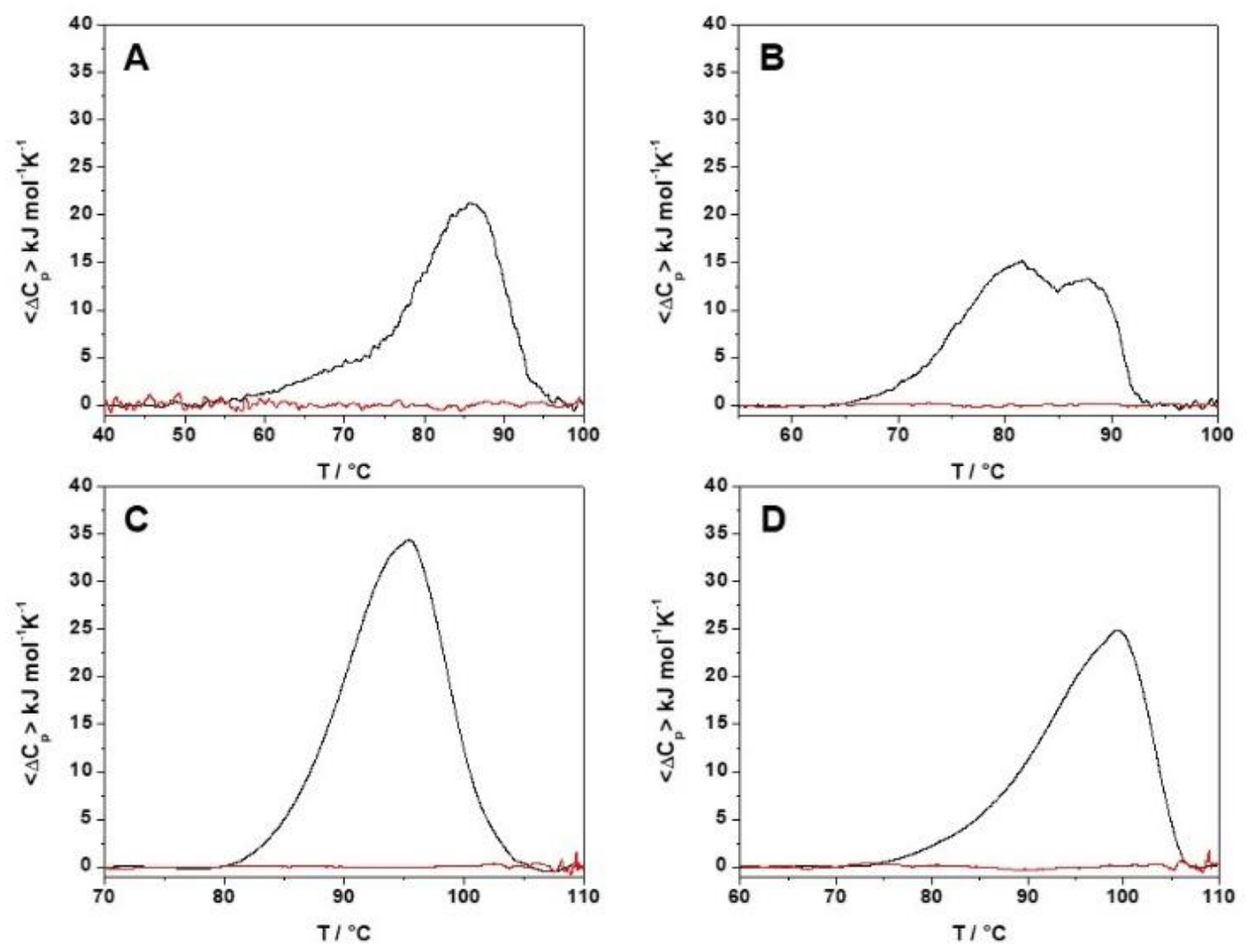

Fig 3. DSC first heating (black lines) and cooling (red lines) profiles of (A) Rf-TGGGAG, (B) RfGGGAG, (C) TGGGAG-Rf and (D) TGGGA-Rf. All the experiments were carried out at $2 \times 10^{-4} \mathrm{M}$ of ss ODNs in $10 \mathrm{mM}$ potassium phosphate buffer $+100 \mathrm{mM} \mathrm{KCl}(\mathrm{pH} 7.0)$. 
In Table 1, the melting temperatures and the enthalpy changes relative to the G-quadruplex dissociation process were reported. Inspection of Table 1 reveals that all the modified G-quadruplexes have a higher thermal stability $\left(\mathrm{T}_{\mathrm{m}}\right)$ compared with the natural sequence, particularly the stabilization is higher when the $\mathrm{Rf}$ residue is introduced at the 3 '-end.

Table 1. Thermodynamic parameters for the G-quadruplex dissociation.

\section{Sequences}
$\Delta \mathbf{H}_{\mathbf{d}}$
$\left(\mathrm{kJ} \mathrm{mol}^{-1}\right.$ of G-quadruplex)

TGGGAG

(A)RfTGGGAG

(B) Rf-GGGAG

(C) TGGGAG-Rf

(D) TGGGA-Rf
327

324

250

365

355
$\mathbf{T}_{\mathbf{m}}$

67.7

85.6

81.7-88

95.3

99.3

Errors on enthalpy changes are within $5 \%$, errors on Tm are within $0.2{ }^{\circ} \mathrm{C}$

However, differently from the other sequences, the DSC profile of the sequence $\mathbf{B}$ shows at least two well resolved DSC peaks and an anomalous low total enthalpy change, this result, in agreement with electrophoresis and CD results, suggests by the presence of multiple species and a not complete formation of a single well defined tetramolecular complex. For this reason, it is not possible to assign the corresponding total enthalpy change to a single well defined process (i.e. the G-quadruplex dissociation) and we preferred not to further discuss the enthalpy change for this sequence. Inspection of the enthalpy changes for the other sequences reveals that when the $\mathrm{Rf}$ is introduced at the 3'-end (sequences $\mathbf{C}$ and D), there is and enthalpy increase (in comparison with the reference sequence) for the G-quadruplex dissociation of $\Delta \Delta \mathrm{H} \sim 40 \mathrm{~kJ} / \mathrm{mol}$ and $\sim 30 \mathrm{~kJ} / \mathrm{mol}$ for $\mathbf{C}$ and $\mathbf{D}$, respectively. This enthalpy increase can be assigned to the contribution of the $\mathrm{Rf}$ residue in the sequence $\mathbf{C}$ in which the $\mathrm{Rf}$ residue is added to the unmodified d(TGGGAG) sequence. However, in the sequence D, the Rf residue replaces a $G$ residue of the reference sequence suggesting that its enthalpic contribution to the G-quadruplex stabilization could be even higher than the observed $\Delta \Delta \mathrm{H}$. Taken together these data reveal that the four $\mathrm{Rf}$ residues introduced at the 3 '-end are able to form additional stabilizing interactions, energetically almost comparable to the enthalpic contribution of a G-tetrad. 


\subsection{Quenching of riboflavin fluorescence depending on $G 4$ or ss arrangements formed by Rf-modified}

sequences

In order to verify if the $\mathrm{Rf}$ residue is able to form stacking interaction with the adjacent bases within the G-quadruplex structures, we exploit the properties of the Rf fluorescence in both ss and G4 forms. In this frame, it has been reported that Rf fluorescence is more quenched when stacked in a G-quadruplex structure than in the unstructured single strand form.[29,27] Hence, the fluorescence emission spectra of all Rf-modified sequences were collected before denaturation of samples and after fast cooling at room temperature. The experiments were conducted at low G-quadruplex concentrations $(\sim 1 \mu \mathrm{M})$. In these conditions, we can assume that, after denaturation, the G-quadruplexes were not formed upon cooling. A significant quenching of riboflavin fluorescence $(\lambda=530 \mathrm{~nm})$ has been found for the sequences $\mathbf{C}$ and D when structured in G4 respect to their dissociated ss form, whereas, a smaller quenching was observed for the G4 of $\mathbf{A}$ and none for $\mathbf{B}$ (Fig. 4).
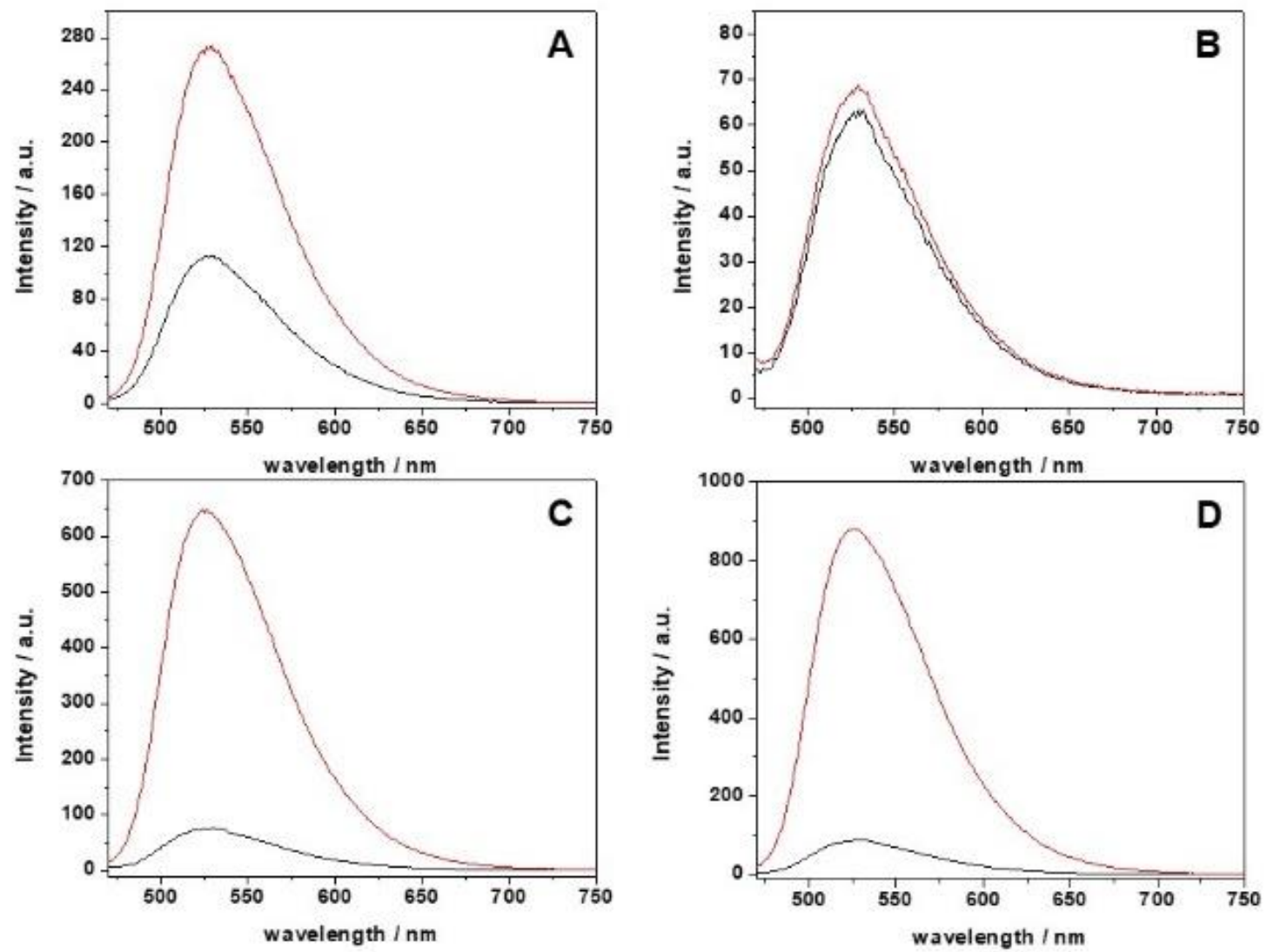

Fig. 4 Fluorescence emission spectra of (A) Rf-TGGGAG, (B) Rf-GGGAG, (C) TGGGAG-Rf and (D) TGGGA-Rf at the temperature of $25^{\circ} \mathrm{C}$ (black lines) and after heating at $100{ }^{\circ} \mathrm{C}$ and fast re-cooling at $25^{\circ} \mathrm{C}$ (red lines). The spectra were recorded after excitation at $450 \mathrm{~nm}$, by using a $1-\mathrm{cm}$ path length 
quartz cuvette. All the spectra were recorded at $40 \times 10^{-5} \mathrm{M}$ of ss ODNs in $10 \mathrm{mM}$ potassium phosphate buffer + $100 \mathrm{mM} \mathrm{KCl}(\mathrm{pH} 7.0)$.

These findings reveal that in the $\mathbf{C}$ and $\mathbf{D}$ sequences, the $\mathrm{Rf}$ residue is able to establish significant stacking interactions with the adjacent tetrads of G4 structures as confirmed by the higher enthalpy of dissociation measured by DSC experiments.

\subsection{Anti-HIV activity of Rf-modified sequences}

The anti-HIV activity and cellular cytotoxicity of the Rf-modified oligodeoxynucleotides were evaluated against HIV-1 NL4.3 and HIV-2 ROD replication in a CD4 ${ }^{+}$T cell line MT-4 cell cultures using the 3-(4,5- dimethylthiazol-2-yl)-2,5- diphenyltetrazolium bromide (MTT) method as described previously by Pauwels et al.[38] The Rf-modified sequences A and B exhibited moderate HIV-1 and HIV-2 activity as reported by the $\mathrm{IC}_{50}$ in the Table 2 . The sequences $\mathbf{C}$ and $\mathbf{D}$ modified at 3 '-end did not show anti-HIV activity.

Table 2. $\mathrm{IC}_{50}$ and $\mathrm{CC}_{50}$ values of Rf-modified oligodeoxynucleotides.

\begin{tabular}{lllll}
\hline Compound & Unit & $\begin{array}{l}\text { IC50 HIV-1 } \\
(\mathbf{N L 4 . 3})\end{array}$ & $\begin{array}{l}\text { IC50 HIV-2 } \\
(\text { ROD) }\end{array}$ & C 50 \\
A & $\mu \mathrm{M}$ & 2.59 & 4.47 & $>20$ \\
B & $\mu \mathrm{M}$ & 8.15 & 8.77 & $>20$ \\
C & $\mu \mathrm{M}$ & 20 & $>20$ & $>20$ \\
D & $\mu \mathrm{M}$ & $>20$ & $>20$ & $>20$ \\
AMD3100 & $n g / m l$ & 12.26 & 17.92 & $>1000$ \\
\hline
\end{tabular}

$\mathrm{IC}_{50}: 50 \%$ Inhibitory concentration or compound concentration required to inhibit HIV-induced cytopathogenic effect evaluated in the $\mathrm{CD}^{+} \mathrm{MT}-4 \mathrm{~T}$ cell line. $\mathrm{CC}_{50}$ : 50\% Cytotoxic concentration of the compounds in parallel evaluated in this cell line. 


\section{Conclusions}

In conclusion, we report here, the synthesis of a riboflavin mimic nucleoside and its insertion into a model sequence forming tetramolecular G-quadruplex structure. All secondary structures formed by Rfmodified sequences have been characterized by native PAGE, CD, DSC and fluorescence analyses. Also the anti-HIV activity of all rf-modified sequences has been evaluated. CD and native PAGE data have reported similar behavior to the parallel G-quadruplex structure for almost all modified sequences. The melting temperature (Tm) of all Rf-modified sequences results to be higher than that of natural one, in particular the insertion of Rf unit at 3'-end of the d(TGGGAG) sequence (C and $\mathbf{D}$ sequences) has more effect on the stability of G-quadruplex than modification at the 5'-end (A and $\mathbf{B}$ sequences).

Consistent with these results, DSC and fluorescence analyses have revealed the ability of Rf units inserted at 3'-end of the lead sequence to form additional stabilizing interaction energetically similar to that of a G-tetrad. In particular DSC experiments highlighted the higher enthalpy of G4 dissociation of sequences $\mathbf{C}$ and $\mathbf{D}$ respect to the natural d(TGGGAG) one due to the stacking interactions of Rf-moiety with the adjacent bases within the G-quadruplex structure. These preliminary findings reveal the ability of $\mathrm{Rf}$ residue to establish significant stacking interactions with the adjacent tetrads of G4 structures.

Future studies will be address to the characterization of these interactions and, in turn, to assess the potential formation of Rf-tetrad in a large variety of relevant G-quadruplexes. 


\section{Materials and Methods}

\subsection{General methods}

Riboflavin (1) was purchased from Sigma-Aldrich - Italy. HPLC-grade $\mathrm{CH}_{3} \mathrm{CN}$ was purchased from Carlo Erba Reagents and Sigma-Aldrich, respectively. Unless otherwise indicated, other chemicals were obtained from Sigma-Aldrich.

Reactions were monitored by TLC (precoated silica gel plates F254, Merck) and column chromatography (Merck Kieselgel 60, 70-230 mesh). Analysis and purification was performed on a Shimadzu LC-8A PLC system equipped with a Shimadzu SCL-10A VP System control and a Shimadzu SPD-10A VP UV-vis detector. HPLC purifications were carried out on Phenomenex RP18 column (Gemini, $10 \mu \mathrm{m} \mathrm{C18(2),250} \mathrm{mm} \times 21.2 \mathrm{~mm}$ i.d.) using a linear gradient of $\mathrm{CH}_{3} \mathrm{CN}$ in $0.1 \mathrm{M}$ TEAA in $\mathrm{H}_{2} \mathrm{O}$ (pH 7.0) from $20 \%$ to $100 \%$ over $30 \mathrm{~min}$ at a flow rate of $7 \mathrm{~mL} / \mathrm{min}$ with detection at 260 and 360 nm. MALDI-TOF mass spectrometric analyses were performed on AB SCIEX TOF/TOF 5800.

Desalting was conducted using gel filtration chromatography on a Sephadex G10 column, eluted with $\mathrm{H}_{2} \mathrm{O} / \mathrm{EtOH} 4: 1(\mathrm{v} / \mathrm{v})$.

\subsection{Synthesis of riboflavin building blocks}

4.2.1. Synthesis of 2',4'-O-benzylidene-riboflavin (2)

Riboflavin (1) (2 g, $5.31 \mathrm{mmol})$ was dissolved in dry DMF (25 mL), (+)-camphor-10- sulfonic acid (CSA) $(62 \mathrm{mg}, 0.26 \mathrm{mmol})$ and $796 \mu \mathrm{L}$ of benzaldehyde dimethyl acetal $(5.31 \mathrm{mmol})$ were added. The reaction was taken at $80{ }^{\circ} \mathrm{C}$ in the dark for a night. The reaction was monitorated by TLC (dichloromethane-methanol, 9:1, v:v) and quenched at room temperature by addition of triethylamine until neutrality. After evaporation of solvents, the residue concentrated under reduced pressure and subsequently purified on silica gel with dichloromethane-methanol (95:5 to 90:10) to yield compound 2 (537 mg, $1.16 \mathrm{mmol}, 22 \%)$.

Compound 2: ${ }^{1} \mathrm{H}$ NMR (DMSO-d $d_{6} 400 \mathrm{MHz}$, r.t.) 8.02 ppm (1H, $s$, aromatic-Rf); 7.82 ppm (1H, $s$, aromatic-Rf); $5.52 \mathrm{ppm}\left(1 \mathrm{H}, s, \mathrm{H}_{6}{ }^{\prime}\right) ; 5.20$ and $4.85 \mathrm{ppm}\left(2 \mathrm{H}, m, \mathrm{H}_{1}{ }^{\prime}\right) ; 4.18 \mathrm{ppm}\left(1 \mathrm{H}, m, \mathrm{H}_{2}{ }^{\prime}\right) ; 3.80-3.73$ ppm $\left(1 \mathrm{H}, m, \mathrm{H}_{5}{ }^{\prime}\right) ; 3.65$ ppm $\left(1 \mathrm{H}, m, \mathrm{H}_{4}{ }^{\prime}\right) ; 3.60-3.41 \mathrm{ppm}\left(2 \mathrm{H}\right.$, overlapped signals, $\mathrm{H}_{5}{ }^{\prime}$ and $\left.\mathrm{H}_{3}{ }^{\prime}\right) ; 2.39$ ppm (3H, $\left.s, \mathrm{CH}_{3}-\mathrm{Rf}\right) ; 2.45$ ppm (3H, $\left.s, \mathrm{CH}_{3}-\mathrm{Rf}\right) .{ }^{13} \mathrm{C}$ NMR (DMSO- d6, $100 \mathrm{MHz}$, r.t.): $\delta=160.3 ; 155.8$; $151.0 ; 146.0 ; 138.3 ; 137.5 ; 136.2 ; 134.1 ; 132.4 ; 130.9 ; 128.9 ; 128.1 ; 126.5 ; 118.7 ; 100.0 ; 82.5 ; 78.8$; $63.8 ; 61.7 ; 46.8 ; 21.0$ and 19.2 ppm.5 Hz, 1H, H-3); 5.33 (d, J=6.0 Hz, 1H, H-7"); 4.08 (m, 1H, H-8"); 3.78 (s, 6H, OC $\underline{H}_{3}$ of 4,4'-dimethoxytriphenylmethyl); 3.60-3.58 (overlapped signals, $4 \mathrm{H}, \mathrm{OC}_{3}$ of silibinin and H-9"a); 3.54 ( $b r d, J=11.0 \mathrm{~Hz}, 1 \mathrm{H}, \mathrm{H}-9 " \mathrm{~b}) ; 2.92-2.84$ ( $m, 3 \mathrm{H}, \mathrm{C} \underline{\mathrm{H}}$ of isobutyryl groups in 
5, 7 e 4"); 2.80-2.77 ( $m, 1 \mathrm{H}, \mathrm{C} \underline{\mathrm{H}}$ of isobutyryl group in 3); 1.41-1.25 (m, 18H, $\underline{\mathrm{C}}_{3}$ of isobutyryl group in 5, 7 e 4"); $1.15-1.10\left(m, 6 \mathrm{H}, \underline{\mathrm{CH}}_{3}\right.$ of isobutyryl group in 3$) \mathrm{ppm} .{ }^{13} \mathrm{C} \mathrm{NMR}\left(\mathrm{CDCl}_{3}, 125 \mathrm{MHz}\right.$, r.t., mixture of diastereoisomers): $\delta=185.2 ; 175.3 ; 175.0 ; 174.5 ; 169.1 ; 168.4 ; 167.7 ; 162.4 ; 158.1 ; 156.2$; $151.3 ; 150.9 ; 148.9 ; 148.7 ; 144.8 ; 144.6 ; 143.8 ; 143.7 ; 139.9 ; 136.7 ; 136.5 ; 135.7 ; 135.3 ; 134.5 ; 130.0$; 129.7; 128.0; 127.7; 127.6; 124.0; 123.8; 122.6; 120.7; 119.7; 113.1; 113.0; 111.3; 111.2; 111.0; 110.8; $110.5 ; 108.9 ; 86.0 ; 80.9 ; 77.5 ; 76.8 ; 76.4 ; 73.1 ; 62.6 ; 55.4 ; 55.1 ; 55.0 ; 21.0 ; 20.9 ; 20.6 ; 20.4 ; 20.0 ; 19.6$; 19.0; 18.8; 18.7; 18.6 ppm. ESI-MS (positive ions): $\mathrm{m} / 2$ calculated for $\mathrm{C}_{54} \mathrm{H}_{48} \mathrm{O}_{16}=952.29$; found: 976.25 $[\mathrm{MNa}]^{+}$.

\subsubsection{Synthesis of 5'-O-DMT-2',4'-O-benzylidene-riboflavin (3)}

Compound 2 (426 mg, $0.92 \mathrm{mmol}$ ) was dissolved in dry pyridine $(3 \mathrm{~mL}), 4,4$ '- dimethoxytrityl chloride (279 $\mathrm{mg}, 0.82 \mathrm{mmol}$ ) was added at room temperature. After $2 \mathrm{~h}$, the reaction was quenched by addition of methanol $(3 \mathrm{~mL})$. Solvents were evaporated, and residual pyridine was coevaporated with toluene. Dichloromethane was added to the residue and washed two times with water. The combined organic extracts were dried over $\mathrm{Na}_{2} \mathrm{SO}_{4}$, filtered and concentrated under reduced pressure. The residue was purified on silica gel in dichloromethane-methanol (97:30 to 95:50 + 1\% triethylamine). The 5'-O-DMT2',4'-O-benzylidene-riboflavin 3 was obtained in good yield (667 mg, 0,87 mmol, 95\%).

Compound 3: ${ }^{1} \mathrm{H}$ NMR $\left(\mathrm{CDCl}_{3}, 400 \mathrm{MHz}\right): 8.07 \mathrm{ppm}(1 \mathrm{H}, s$, aromatic-Rf), $7.95 \mathrm{ppm}(1 \mathrm{H}, s$, aromaticRf); 7.37-7.10 ppm (9H, $m$, aromatic-DMT), 6.82-6.79 ppm (4H, $m, \mathrm{H}_{m}$ DMT), $5.68 \mathrm{ppm}\left(1 \mathrm{H}, s, \mathrm{H}_{6^{\prime}}\right)$; 5.21-4.83 ppm (2H, m, $\left.\mathrm{H}_{1}{ }^{\prime}\right) ; 4.28$ ppm $\left(1 \mathrm{H}, m, \mathrm{H}_{2}\right)$; 3.97 ppm $\left(1 \mathrm{H}, m, \mathrm{H}_{4}{ }^{\prime}\right) ; 3.80$ ppm $\left(6 \mathrm{H}, s, \mathrm{OCH}_{3}{ }^{-}\right.$ DMT); 3.53 ppm (1H, m, $\left.\mathrm{H}_{3}{ }^{\prime}\right) ; 3.52$ ppm (1H, $\left.m, \mathrm{H}_{5}{ }^{\prime}\right) 3.41$ ppm (1H, $\left.m, \mathrm{H}_{5}{ }^{\prime}\right) ; 2.46$ ppm (3H, $\left.s, \mathrm{CH}_{3}-\mathrm{Rf}\right)$; $2.43 \mathrm{ppm}\left(3 \mathrm{H}, s, \mathrm{CH}_{3}-\mathrm{Rf}\right) .{ }^{13} \mathrm{C} \mathrm{NMR}\left(\mathrm{CDCl}_{3}, 100 \mathrm{MHz}\right): \delta=159.2,158.4,154.4,148.1,144.9,137.5$, $137.4,136.1,136.0,135.5,135.3,132.3,132.2,130.2,130.1,128.8,128.2,128.0,127.7,126.7,125.9$, $118.2,113.0,113.4,100.4,86.0,80.4,80.2,63.8,55.2,47.5,21.3$ and 19.5 ppm.

\subsubsection{Synthesis of 5'-O-DMT-2',4'-O-benzylidene-riboflavin-phosphoramidite (4)}

To 5'-O-DMT-2',4'-O-benzylidene-riboflavin $3(145 \mathrm{mg}, 0.19 \mathrm{mmol})$ dissolved in anhydrous dichloromethane $(4 \mathrm{~mL})$, DIPEA $(131 \mu \mathrm{L}, 0.76 \mathrm{mmol})$ and 2-cyanoethyl-N,N-diisopropylaminochlorophosphoramidite $(116 \mu \mathrm{L}, 0.28 \mathrm{mmol})$ were added. After $1 \mathrm{~h}$, the solution was concentrated in vacuo and purified on column chromatography with ethyl acetate-hexane (9:1 with $3 \%$ trimethylamine) afforded the 5'-O-DMT-2',4'-O-benzylidene-riboflavin-phosphoramidite 4 (146 mg, $0.15 \mathrm{mmol}, 80 \%$ ). The characterization of the intermediate phosphoramidite 4 was carried out by ${ }^{31} \mathrm{P}-\mathrm{NMR}$ and ESI-MS 
analyses. ${ }^{31} \mathrm{P}-\mathrm{NMR}\left(161.98 \mathrm{MHz}, \mathrm{CDCl}_{3}\right.$, r. t., mixture of diastereoisomers) $\delta=149.91 ; 149.41 \mathrm{ppm}$; ESI-MS (positive ion) $\mathrm{m} / \mathrm{z}$ calcd for $\mathrm{C}_{54} \mathrm{H}_{59} \mathrm{~N}_{6} \mathrm{O} 9 \mathrm{P}=966,41$, found 967,41 [M-H] ${ }^{+}$.

\subsubsection{Synthesis of 3'-O-succinyl-5'-O-DMT-2',4'-O-benzylidene-riboflavin (5)}

5'-O-DMT-2',4'-O-benzylidene-riboflavin 3 (290 mg, $0.37 \mathrm{mmol})$ was dissolved in dry pyridine (2 $\mathrm{mL})$, triethylamine (TEA) $(260 \mu \mathrm{L}, 1.89 \mathrm{mmol})$ and $150 \mathrm{mg}$ of succinyl anhydride $(1.48 \mathrm{mmol})$ were added. The reaction was stirred at $50{ }^{\circ} \mathrm{C}$ for $2 \mathrm{~h}$. After $2 \mathrm{~h}$, the mixture was extracted two times with dichloromethane and water. The combined organic extracts were dried over $\mathrm{Na}_{2} \mathrm{SO}_{4}$, filtered and concentrated under reduced pressure. The residue was purified on silica gel in dichloromethane-methanol (97:30 to $95: 50+1 \%$ triethylamine). The 3'- $O$-succinyl-5'-O-DMT-2',4'-O-benzylidene-riboflavin 5 was obtained in good yield $(0.28 \mathrm{mmol}, 76 \%)$.

Compound 5: ${ }^{1} \mathrm{H}$ NMR (CDCl $\left.3,400 \mathrm{MHz}\right): 8.03$ ppm (1H, s, aromatic-Rf); 7.87 (1H, s, aromatic-Rf); 7.50-7.11 ppm (9H, $m$, aromatic-DMT), 6.84 ppm (4H, $d, \mathrm{~J}=8.7 \mathrm{~Hz}, \mathrm{H}_{m}$ DMT); $5.45 \mathrm{ppm}\left(1 \mathrm{H}, s, \mathrm{H}_{6}{ }^{\prime}\right)$; 5.37-5.28 ppm (2H, overlapped signals, $\mathrm{H}_{3}$, and $\mathrm{H}_{1}$ ) $)$; 4.58-4.42 ppm (2H, overlapped signals, $\mathrm{H}_{2}$, and $\left.\mathrm{H}_{1}{ }^{\prime}\right)$; $4.07 \mathrm{ppm}\left(1 \mathrm{H}, m, \mathrm{H}_{4}{ }^{\prime}\right) ; 3.82 \mathrm{ppm}\left(6 \mathrm{H}, s, \mathrm{OCH}_{3}-\mathrm{DMT}\right) ; 3.38 \mathrm{ppm}\left(1 \mathrm{H}, m, \mathrm{H}_{5}\right.$ ) ; $3.22 \mathrm{ppm}\left(1 \mathrm{H}, m, \mathrm{H}_{5}{ }^{\prime}\right)$; 2.83-2.51 ppm (4H, $m, \mathrm{CH}_{2}$ succinyl); $2.46 \mathrm{ppm}\left(6 \mathrm{H}, s, \mathrm{CH}_{3}-\mathrm{Rf}\right) .{ }^{13} \mathrm{C} \mathrm{NMR}\left(\mathrm{CDCl}_{3}, 100 \mathrm{MHz}\right): \delta=$ 175.3, 172.0, 159.2, 158.4, 154. 4, 148.1, 144.9, 137.5, 137.4, 136.1, 136.0, 135.5, 135.3, 132.3, 132.2, 130.2 , 130.1, 128.8, 128.2, 128.0, 127.7, 126.7, 125.9, 118.2, 113.0, 113.4, 99.5, 86.0, 78.0, 75.9, 65.5, $62.8,54.7,47.9,29.4,30.4,21.2$ and $19.4 \mathrm{ppm}$.

\subsection{Synthesis of Rf-functionalized solid support (6)}

In a typical experiment to $150 \mathrm{mg}$ of $\mathrm{HL}$ CPG-NH $2(108 \mathrm{umol} / \mathrm{g}, 0.09 \mathrm{mmol})$ suspended in $1.0 \mathrm{~mL}$ of dry pyridine and $50 \mathrm{uL}$ of DIPEA $(0.27 \mathrm{mmol})$, a mixture of $5(0.27 \mathrm{mmol})$, DCCI $(56 \mathrm{mg}, 0.27 \mathrm{mmol})$, DIPEA $(50 \mu \mathrm{L}, 0.27 \mathrm{mmol})$, and dry pyridine $(500 \mathrm{uL})$ was added and shaken at room temperature for 72 hours. After exhaustive washings with pyridine, DMF, ACN, DCM and $\mathrm{Et}_{2} \mathrm{O}$, the support was dried under reduced pressure. DMT tests performed on dried and weighed samples of resulting support 6 allowed to determine the incorporation yields of derivative 5, onto the resin, which resulted to be in the range of $0.04-0.05 \mathrm{mmol} / \mathrm{g}$. After treatment with $1.0 \mathrm{~mL}$ of acetic anhydride/pyridine $(1: 1, \mathrm{v} / \mathrm{v})$ at r.t. for 1 hour (capping), the resin was washed exhaustively with $\mathrm{DCM}, \mathrm{CH}_{3} \mathrm{OH}$ and $\mathrm{Et}_{2} \mathrm{O}$, dried under reduced pressure and used for automated syntheses of sequences $\mathbf{C}$ and $\mathbf{D}$.

\subsection{Synthesis and HPLC purification of Rf-modified ODN sequences}

Oligomers A and B were synthesised starting with functionalised CPG support with $0.1 \mathrm{meq} / \mathrm{g}$ initial loading, on which the sequences d(TGGGAG) and d(GGGAG) were assembled in a standard manner. 
An additional coupling with phosphoramidite building block 4 was then performed. Oligomers C and D were synthesised starting from the support $\mathbf{6}$ in a standard manner.

Oligomers A-D were detached from the solid support and deprotected by treatment with trimethylamine /pyridine $(1: 1, \mathrm{v} / \mathrm{v})$ at $50{ }^{\circ} \mathrm{C}$ for $1 \mathrm{~h}$, followed by treatment with conc. aq. ammonia at 50 ${ }^{\circ} \mathrm{C}$ for $5 \mathrm{~h}$. The combined filtrates and washings were concentrated under reduced pressure, re-dissolved in water, analysed and purified by HPLC. Purification of the crude modified oligonucleotides A-D was carried out on Phenomenex RP18 column (Gemini, $10 \mu \mathrm{m} \mathrm{C18(2),} 250 \mathrm{~mm} \times 21.2 \mathrm{~mm}$ ) using a linear gradient of $\mathrm{CH}_{3} \mathrm{CN}$ in $0.1 \mathrm{M}$ TEAA in $\mathrm{H}_{2} \mathrm{O}$, pH 7.0 from 20 to $100 \%$ over 30 min at flow rate of 7 $\mathrm{mL} / \mathrm{min}$ with detection at 260 and $360 \mathrm{~nm}$. The A-D ODNs were desalted on a Sephadex G10 column eluted with $\mathrm{H}_{2} \mathrm{O} / \mathrm{EtOH}$ 4:1 (v/v). The modified ODNs were obtained with an average yield of 25-31\%. MS (MALDI-TOF) m/z calcd. for A [d(Rf-TGGGAG)] and C [d(TGGGAG-Rf]: $[\mathrm{M}]_{\text {calc. }}=2398.69 \mathrm{~m} / \mathrm{z}$; $[\mathrm{M}-\mathrm{H}]^{-}{ }_{\exp }=2397.34 \mathrm{~m} / \mathrm{z}$.

MS (MALDI-TOF) m/z calcd. for B [d(Rf-GGGAG)]: [M] $]_{\text {calc }}=2094.50 \mathrm{~m} / \mathrm{z} ;[\mathrm{M}-\mathrm{H}]^{-}{ }_{\exp }=2093.99 \mathrm{~m} / \mathrm{z}$. MS (MALDI-TOF) m/z calcd. for D [d(TGGGA-Rf)]: [M] $]_{\text {calc }}=2069.49 \mathrm{~m} / \mathrm{z} ;[\mathrm{M}-\mathrm{H}]^{-}{ }_{\mathrm{exp}}=2068.73 \mathrm{~m} / \mathrm{z}$.

\subsection{Characterization of $R f$-modified $G$-quadruplexes}

\subsubsection{G-quadruplex preparation}

Stock ODNs solutions were prepared at single stranded concentration of $1 \mathrm{mM}$ in $10 \mathrm{mM}$ $\mathrm{KH}_{2} \mathrm{PO}_{4} / \mathrm{K}_{2} \mathrm{HPO}_{4}+100 \mathrm{mM} \mathrm{KCl}$ buffer. Annealing experiments were performed at $80{ }^{\circ} \mathrm{C}$ heating for 5 minutes and then a fast cooling to room temperature was carried out. After annealing, the G-rich oligonucleotides arrange in G-quadruplex structure stabilized by potassium coordination. The solutions were stored at $8{ }^{\circ} \mathrm{C}$ for 14 days before all experiments. The concentration of the dissolved oligonucleotides A-D and natural one was determined by UV measurements.

\subsubsection{Native gel electrophoresis}

All stock solutions of (A-D) were loaded on the gels after dilution to $50 \mu \mathrm{M}$ (ss concentration) and with the addition of $25 \%$ of glycerol. The oligonucleotide $\mathrm{d}\left(\mathrm{T}_{6}\right)$ was used as a single-stranded 6-mer marker and $\mathrm{d}\left(\mathrm{TG}_{4} \mathrm{~T}\right)$ as a tetramolecular G-quadruplex one, $\left[\mathrm{d}\left(\mathrm{TG}_{4} \mathrm{~T}\right)\right]_{4}$. Native gel electrophoresis was performed on $15 \%$ polyacrylamide gel (acrylamide/bi-acrylamide 19:1) and the running buffer (TBE $0.5 \mathrm{X}$ ) was supported by $10 \mathrm{mM} \mathrm{KCl}$ in order to preserve the native conditions. The gel was run at $26^{\circ} \mathrm{C}$ at constant voltage $(100 \mathrm{~V})$ for $2.5 \mathrm{~h}$. The bands were visualized by UV shadowing after stained with Stains All (Sigma-Aldrich) according to the manufacturer's instructions. 


\subsubsection{Circular dichroism (CD)}

CD spectra were recorded on a Jasco J-715 spectropolarimeter equipped with a Peltier-type temperature control system (model PTC-348WI), using a quartz cuvette with a path length of $0.1 \mathrm{~cm}$. CD parameters for spectra recording were the following: spectral window 220-320 nm, data pitch $1 \mathrm{~nm}$, band width $2 \mathrm{~nm}$, response $4 \mathrm{~s}$, scanning speed $40 \mathrm{~nm} / \mathrm{min}$, temperature $10{ }^{\circ} \mathrm{C}, 3$ accumulations. All sequences were analysed at $1 \times 10^{-4} \mathrm{M}$ single stranded concentration in $10 \mathrm{mM} \mathrm{KH} \mathrm{PO}_{4} / \mathrm{K}_{2} \mathrm{HPO}_{4}+100$ $\mathrm{mM} \mathrm{KCl}$ buffer.

\subsubsection{Differential Scanning Calorimetry (DSC)}

DSC measurements were performed by means of NanoDSC from TA Instruments (New Castle, DE, USA). The excess molar heat capacity function $(<\Delta \mathrm{Cp}>)$ was obtained after the subtraction of the baseline. A buffer-buffer scan was subtracted from the sample scan. Briefly a volume of $300 \mu \mathrm{L}$ of Rfmodified G-quadruplex sample at concentrations ranging from $35 \mu \mathrm{M}$ to $135 \mu \mathrm{M}$ (concentration per mol of G-quadruplex) was placed in the calorimetry vessel. Successive heating scans were performed in the range $25-110{ }^{\circ} \mathrm{C}$ at scan rate of $1{ }^{\circ} \mathrm{C} / \mathrm{min}$ to check the reversibility of the melting process. The obtained DSC data were analyzed by means of the NanoAnalyze software supplied with the instrument and plotted using the Origin software package (OriginLab, Northampton, MA, USA). The transition enthalpies, $\Delta \mathrm{H}^{\circ}$, were obtained by integrating the area under the heat capacity vs temperature curves. The enthalpy change values are the averages of at least three different heating experiments.

\subsubsection{Fluorescence spectroscopy}

Fluorescence emission spectra of Rf-modified sequences were acquired by means of Fluoromax-4 fluorimeter from Horiba Scientific (Edison, NJ, USA) by using a 1-cm path length quartz cuvette. The sample concentrations were around $4 \mu \mathrm{M}$ single strand concentration. The samples were excited at the wavelength of $450 \mathrm{~nm}$, and emission spectra were acquired in the range 470-750 $\mathrm{nm}$. The excitation and emission slits of the monochromators were set to $2 \mathrm{~nm}$ and $6 \mathrm{~nm}$, respectively. The temperature was controlled by means of a Peltier system that ensures an accuracy of $\pm 0.1{ }^{\circ} \mathrm{C}$. During the acquisition, the samples were under gentle stirring. For each sample two spectra were recorded: the first one at the temperature of $25^{\circ} \mathrm{C}$ and the second one after heating the sample at $100{ }^{\circ} \mathrm{C}$ and fast cooling at $25{ }^{\circ} \mathrm{C}$.

\subsubsection{Anti-HIV assay}

The anti-HIV activity and cellular cytotoxicity of the Rf-modified oligodeoxynucleotides were evaluated against HIV-1 NL4.3 and HIV-2 ROD replication in a CD4 ${ }^{+}$T cell line MT-4 cell cultures 
using the 3-(4,5- dimethylthiazol-2-yl)-2,5- diphenyltetrazolium bromide (MTT) method as described previously by Pauwels et al.[38]

\section{Conflicts of interest}

There are no conflicts to declare.

\section{Abbreviations}

\begin{tabular}{|c|c|}
\hline $\mathrm{Rf}$ & Riboflavin \\
\hline G4 & G-quadruplex \\
\hline $\mathrm{CD}$ & Circular dichroism \\
\hline DSC & Differential scanning calorimetry \\
\hline PAGE & Polyacrylamide gel electrophoresis \\
\hline ODNs & Oligodeoxynucleotides \\
\hline DMT & 4,4'-dimethoxytrityl \\
\hline $\mathrm{DMF}$ & Dimethylformamide \\
\hline DIPEA & N,N-Diisopropylethylamine \\
\hline DCCI & N,N'-Dicyclohexylcarbodiimide \\
\hline $\mathrm{CPG}$ & Controlled Pore Glass \\
\hline
\end{tabular}

RP-HPLC Reverse Phase-High Performance Liquid Chromatography 
HIV Human Immunodeficiency Virus

TBE buffer Tris-borate-EDTA buffer

ACN Acetonitrile

DCM Dichloromethane

TEAA Triethylammonium acetate

\section{Acknowledgements}

We acknowledge AIPRAS Onlus (Associazione Italiana per la Promozione delle Ricerche sull'Ambiente e la Saluta umana) and the KULeuven (grant no. PF/10/018) and the Fonds voor Wetenschappelijk Onderzoek (FWO, grant no. G.485.08).for grants in support of this investigation.

\section{Appendix A. Supplementary material: File Romanucci_SI}

\section{References}

[1] S. Balasubramanian, S. Neidle, G-quadruplex nucleic acids as therapeutic targets, Curr. Opin. Chem. Biol. 13 (2009) 345-353. doi:10.1016/j.cbpa.2009.04.637.

[2] S. Neidle, Therapeutic Applications of Quadruplex Nucleic Acids, Academic Press, 2011. https://books.google.com/books?id=Foij6QHHDeAC\&pgis=1 (accessed March 11, 2015).

[3] R. Hänsel-Hertsch, M. Di Antonio, S. Balasubramanian, DNA G-quadruplexes in the human genome: detection, functions and therapeutic potential, Nat. Rev. Mol. Cell Biol. 18 (2017) 279-284. doi:10.1038/nrm.2017.3.

[4] J.L. Huppert, Structure, location and interactions of G-quadruplexes, FEBS J. 277 (2010) 34523458. doi:10.1111/j.1742-4658.2010.07758.x. 
[5] S. Amrane, A. Kerkour, A. Bedrat, B. Vialet, M.-L. Andreola, J.-L. Mergny, Topology of a DNA G-quadruplex structure formed in the HIV-1 promoter: a potential target for anti-HIV drug development., J. Am. Chem. Soc. 136 (2014) 5249-52. doi:10.1021/ja501500c.

[6] A. Virgilio, V. Esposito, A. Randazzo, L. Mayol, A. Galeone, 8-methyl-2'-deoxyguanosine incorporation into parallel DNA quadruplex structures., Nucleic Acids Res. 33 (2005) 6188-95. doi:10.1093/nar/gki924.

[7] J. Gros, F. Rosu, S. Amrane, A. De Cian, V. Gabelica, L. Lacroix, J.L. Mergny, Guanines are a quartet's best friend: Impact of base substitutions on the kinetics and stability of tetramolecular quadruplexes, Nucleic Acids Res. 35 (2007) 3064-3075. doi:10.1093/nar/gkm111.

[8] P.L.T. Tran, A. Virgilio, V. Esposito, G. Citarella, J.-L. Mergny, A. Galeone, Effects of 8methylguanine on structure, stability and kinetics of formation of tetramolecular quadruplexes., Biochimie. 93 (2011) 399-408. doi:10.1016/j.biochi.2010.10.011.

[9] E.B. Pedersen, J.T. Nielsen, C. Nielsen, V. V Filichev, Enhanced anti-HIV-1 activity of Gquadruplexes comprising locked nucleic acids and intercalating nucleic acids., Nucleic Acids Res. 39 (2011) 2470-81. doi:10.1093/nar/gkq1133.

[10] J. Zhou, M. Abramov, F. Liu, S. Amrane, A. Bourdoncle, P. Herdewijn, J.L. Mergny, Effects of six-membered carbohydrate rings on structure, stability, and kinetics of G-quadruplexes, Chem. - A Eur. J. 19 (2013) 14719-14725. doi:10.1002/chem.201301743.

[11] V. Esposito, A. Pepe, R. Filosa, L. Mayol, A. Virgilio, A. Galeone, A novel pyrimidine tetrad contributing to stabilize tetramolecular G-quadruplex structures, Org. Biomol. Chem. 14 (2016) 29382943. doi:10.1039/C5OB02358K.

[12] N.Q. Do, W.J. Chung, T.H.A. Truong, B. Heddi, A.T. Phan, G-quadruplex structure of an antiproliferative DNA sequence, Nucleic Acids Res. 45 (2017) 7487-7493. doi:10.1093/nar/gkx274.

[13] M. Métifiot, S. Amrane, J.-L. Mergny, M.-L. Andreola, Anticancer molecule AS1411 exhibits low nanomolar antiviral activity against HIV-1, Biochimie. 118 (2015) 173-175. doi:10.1016/j.biochi.2015.09.009. 
[14] A. Bouvier-Müller, F. Ducongé, Nucleic acid aptamers for neurodegenerative diseases, Biochimie. 145 (2018) 73-83. doi:10.1016/j.biochi.2017.10.026.

[15] H. Hotoda, M. Koizumi, R. Koga, M. Kaneko, K. Momota, T. Ohmine, d ( TGGGAG ) Possesses Anti-Human Immunodeficiency Virus Type 1 Activity by Forming a G-Quadruplex Structure, J. Med. Chem. 1998. 41 (1998) 3655-3663.

[16] G. Di Fabio, J. D’Onofrio, M. Chiapparelli, B. Hoorelbeke, D. Montesarchio, J. Balzarini, L. De Napoli, Discovery of novel anti-HIV active G-quadruplex-forming oligonucleotides, Chem. Commun. 47 (2011) 2363-2365. doi:10.1039/C0CC04751A.

[17] M. Metifiot, S. Amrane, S. Litvak, M.-L. Andreola, G-quadruplexes in viruses: function and potential therapeutic applications, Nucleic Acids Res. 42 (2014) 12352-12366. doi:10.1093/nar/gku999.

[18] V. Romanucci, A. Zarrelli, S. Liekens, S. Noppen, C. Pannecouque, G. Di Fabio, New findings on the d(TGGGAG) sequence: Surprising anti-HIV-1 activity, Eur. J. Med. Chem. 145 (2018) 425-430. doi:10.1016/j.ejmech.2018.01.005.

[19] V. Romanucci, D. Milardi, T. Campagna, M. Gaglione, A. Messere, A. D’Urso, E. Crisafi, C. La Rosa, A. Zarrelli, J. Balzarini, G. Di Fabio, Synthesis, biophysical characterization and anti-HIV activity of d(TG3AG) Quadruplexes bearing hydrophobic tails at the 5'-end., Bioorg. Med. Chem. 22 (2014) 960-6. doi:10.1016/j.bmc.2013.12.051.

[20] V. Romanucci, M. Gaglione, A. Messere, N. Potenza, A. Zarrelli, S. Noppen, S. Liekens, J. Balzarini, G. Di Fabio, Hairpin oligonucleotides forming G-quadruplexes: New aptamers with anti-HIV activity, Eur. J. Med. Chem. 89 (2015) 51-58. doi:10.1016/j.ejmech.2014.10.030.

[21] V. Romanucci, A. Marchand, O. Mendoza, D. D’Alonzo, A. Zarrelli, V. Gabelica, G. Di Fabio, Kinetic ESI-MS Studies of Potent Anti-HIV Aptamers Based on the G-Quadruplex Forming Sequence d(TGGGAG), ACS Med. Chem. Lett. 7 (2016) 256-260. doi:10.1021/acsmedchemlett.5b00408.

[22] N. Beztsinna, M. Solé, N. Taib, I. Bestel, Bioengineered riboflavin in nanotechnology, Biomaterials. 80 (2016) 121-133. doi:10.1016/j.biomaterials.2015.11.050. 
[23] N. Beztsinna, Y. Tsvetkova, M. Bartneck, T. Lammers, F. Kiessling, I. Bestel, Amphiphilic Phospholipid-Based Riboflavin Derivatives for Tumor Targeting Nanomedicines, Bioconjug. Chem. 27 (2016) 2048-2061. doi:10.1021/acs.bioconjchem.6b00317.

[24] H. Iida, T. Mizoguchi, S.-D. Oh, E. Yashima, Redox-triggered switching of helical chirality of poly(phenylacetylene)s bearing riboflavin pendants, Polym. Chem. 1 (2010) 841. doi:10.1039/c0py00044b.

[25] S. Holladay, Riboflavin-mediated delivery of a macromolecule into cultured human cells, Biochim. Biophys. Acta - Gen. Subj. 1426 (1999) 195-204. doi:10.1016/S0304-4165(98)00147-0.

[26] N.B. Sankaran, S. Nishizawa, T. Seino, K. Yoshimoto, N. Teramae, Abasic-Site-Containing Oligodeoxynucleotides as Aptamers for Riboflavin, Angew. Chemie Int. Ed. 45 (2006) 1563-1568. doi:10.1002/anie.200502979.

[27] L. Xu, N. Sun, L. Zhou, X. Chen, J. Wang, Q. Wang, K. Wang, J. Zhang, R. Pei, A label-free fluorescence assay for potassium ions using riboflavin as a G-quadruplex ligand, Analyst. 140 (2015) 3352-3355. doi:10.1039/C5AN00242G.

[28] C.T. Lauhon, J.W. Szostak, RNA aptamers that bind flavin and nicotinamide redox cofactors, J. Am. Chem. Soc. 117 (1995) 1246-1257. doi:10.1021/ja00109a008.

[29] J. Choi, J. Park, A. Tanaka, M.J. Park, Y.J. Jang, M. Fujitsuka, S.K. Kim, T. Majima, Hole Trapping of G-Quartets in a G-Quadruplex, Angew. Chemie Int. Ed. 52 (2013) 1134-1138. doi:10.1002/anie.201208149.

[30] M. Ashoori, A. Saedisomeolia, Riboflavin (vitamin B 2 ) and oxidative stress: a review, Br. J. Nutr. 111 (2014) 1985-1991. doi:10.1017/S0007114514000178.

[31] J. Jayapaul, M. Hodenius, S. Arns, W. Lederle, T. Lammers, P. Comba, F. Kiessling, J. Gaetjens, FMN-coated fluorescent iron oxide nanoparticles for RCP-mediated targeting and labeling of metabolically active cancer and endothelial cells, Biomaterials. 32 (2011) 5863-5871. doi:10.1016/j.biomaterials.2011.04.056.

[32] A. Schwögler, T. Carell, Toward catalytically active oligonucleotides: synthesis of a flavin nucleotide and its incorporation into DNA., Org. Lett. 2 (2000) 1415-8. doi:10.1021/ol005739s. 
[33] A. Zarrelli, V. Romanucci, M. Greca, L. De Napoli, L. Previtera, G. Di Fabio, New Silybin Scaffold for Chemical Diversification: Synthesis of Novel 23-Phosphodiester Silybin Conjugates, Synlett. 24 (2013) 45-48. doi:10.1055/s-0032-1317688.

[34] J. Zhou, F. Rosu, S. Amrane, D.N. Korkut, V. Gabelica, J.L. Mergny, Assembly of chemically modified G-rich sequences into tetramolecular DNA G-quadruplexes and higher order structures, Methods. 67 (2014) 159-168. doi:10.1016/j.ymeth.2014.01.004.

[35] V. Romanucci, A. Zarrelli, G. Di Fabio, Hotoda's Sequence and Anti-HIV Activity: Where Are We Now?, Molecules. 24 (2019) 1417. doi:10.3390/molecules24071417.

[36] J. D’Onofrio, L. Petraccone, E. Erra, L. Martino, G. Di Fabio, L. De Napoli, C. Giancola, D. Montesarchio, 5'-Modified G-Quadruplex Forming Oligonucleotides Endowed with Anti-HIV Activity: Synthesis and Biophysical Properties, Bioconjug. Chem. 18 (2007) 1194-1204. doi:10.1021/bc070062f.

[37] L. Petraccone, B. Pagano, V. Esposito, A. Randazzo, G. Piccialli, G. Barone, C.A. Mattia, C. Giancola, Thermodynamics and Kinetics of PNA - DNA Quadruplex-Forming Chimeras, J. Am. Chem. Soc. 127 (2005) 16215-16223. doi:0.1021/ja0545923.

[38] R. Pauwels, J. Balzarini, M. Baba, R. Snoeck, D. Schols, P. Herdewijn, J. Desmyter, E. De Clercq, Rapid and automated tetrazolium-based colorimetric assay for the detection of anti-HIV compounds, J. Virol. Methods. 20 (1988) 309-321. doi:10.1016/0166-0934(88)90134-6. 